\title{
Lorcaserin for weight management
}

This article was published in the following Dove Press journal:

Diabetes, Metabolic Syndrome and Obesity:Targets and Therapy

12 June 2013

Number of times this article has been viewed

\author{
James R Taylor \\ Eric Dietrich \\ Jason Powell \\ University of Florida College \\ of Pharmacy, Department of \\ Pharmacotherapy and Translational \\ Research, Gainesville, FL, USA
}

\begin{abstract}
Type 2 diabetes and obesity commonly occur together. Obesity contributes to insulin resistance, a main cause of type 2 diabetes. Modest weight loss reduces glucose, lipids, blood pressure, need for medications, and cardiovascular risk. A number of approaches can be used to achieve weight loss, including lifestyle modification, surgery, and medication. Lorcaserin, a novel antiobesity agent, affects central serotonin subtype $2 \mathrm{~A}$ receptors, resulting in decreased food intake and increased satiety. It has been studied in obese patients with type 2 diabetes and results in an approximately $5.5 \mathrm{~kg}$ weight loss, on average, when used for one year. Headache, back pain, nasopharyngitis, and nausea were the most common adverse effects noted with lorcaserin. Hypoglycemia was more common in the lorcaserin groups in the clinical trials, but none of the episodes were categorized as severe. Based on the results of these studies, lorcaserin was approved at a dose of $10 \mathrm{mg}$ twice daily in patients with a body mass index $\geq 30 \mathrm{~kg} / \mathrm{m}^{2}$ or $\geq 27 \mathrm{~kg} / \mathrm{m}^{2}$ with at least one weight-related comorbidity, such as hypertension, type 2 diabetes mellitus, or dyslipidemia, in addition to a reduced calorie diet and increased physical activity. Lorcaserin is effective for weight loss in obese patients with and without type 2 diabetes, although its specific role in the management of obesity is unclear at this time. This paper reviews the clinical trials of lorcaserin, its use from the patient perspective, and its potential role in the treatment of obesity.
\end{abstract}

Keywords: lorcaserin, obesity, diabetes

\section{Introduction}

Over two thirds of US residents are overweight and about one-third are obese. ${ }^{1}$ Approximately $11 \%$ of the adult US population has type 1 or type 2 diabetes, and this number is expected to double by 2050 . $^{2,3}$ Type 2 diabetes mellitus is the most common form of diabetes, accounting for $90 \%-95 \%$ of all cases. It is more common in adults, but can also occur in children and adolescents. The cause of hyperglycemia in type 2 diabetes is usually a combination of insulin resistance and increased hepatic glucose production. Many factors contribute to the development of insulin resistance and increased hepatic glucose production. Patients with type 2 diabetes are at high risk of cardiovascular disease, so it is important to assess each patient's cardiometabolic risk factors. These include overweight/obesity, smoking, hypertension, hyperlipidemia, sedentary lifestyle, inflammation and hypercoagulation, and demographic factors including age, gender, and race.

The majority of patients with type 2 diabetes are obese or have increased abdominal fat. ${ }^{2,4}$ Obesity is one factor contributing to insulin resistance. However, it is clear that most overweight individuals do not develop type 2 diabetes. Therefore, other
Correspondence: James R Taylor University of Florida College of Pharmacy, PO Box 100486 ,

Gainesville, FL 32610, USA

Tel +l 3522736239

Fax +l 3522736242

Email jtaylor@cop.ufl.edu
Diabetes, Metabolic Syndrome and Obesity:Targets and Therapy 2013:6 209-216

(C) 2013 Taylor et al, publisher and licensee Dove Medical Press Ltd. This is an Open Access article which permits unrestricted noncommercial use, provided the original work is properly cited. 
risk factors must be involved in the development of diabetes in overweight individuals. Little is known in this area, but these risk factors are believed to include inflammatory cytokines (tumor necrosis factor and interleukin-6), insulin resistance, increased free fatty acids, and cellular mechanisms, such as mitochondrial dysfunction. ${ }^{5}$ The exact importance and relationship of these factors with the development of diabetes is poorly defined. Genetic studies may allow us to understand better the complex relationship between these various contributing factors and to identify more precisely individuals who may develop type 2 diabetes.

Successful management of type 2 diabetes typically involves lifestyle modification (nutrition and exercise) and pharmacological therapy, although lifestyle intervention may suffice initially in highly motivated individuals with mild hyperglycemia. ${ }^{6}$ Weight loss of $5 \%-10 \%$ is associated with a significant improvement in glucose, lipids, blood pressure, use of antidiabetic medications, and risk of cardiovascular disease. ${ }^{7}$ Therefore, lifestyle modification and weight loss are not only the foundation of treatment for those with type 2 diabetes, but should also be implemented for those at risk of the disease. In fact, the relevant studies do support lifestyle modification. For example, in the Diabetes Prevention Program, lifestyle intervention resulted in a $58 \%$ reduction in risk of developing type 2 diabetes compared with a $31 \%$ relative risk reduction using metformin. ${ }^{8-11}$ Individuals who enter lifestyle modification programs, during which they routinely meet with qualified health care practitioners, generally lose $7 \%-10 \%$ of their body weight over 4-6 months. ${ }^{12,13}$ Those who do not enter formal programs or who do not complete a program, are not as successful in reducing their weight. Unfortunately, long-term success with lifestyle modification for weight loss is often poor. Some patients are not willing or able to make the necessary lifestyle changes, and for those who are initially successful, many will regain much of the weight lost within a few years. In fact, many regain 30\%-35\% of their lost weight within the first year after completing a treatment program. ${ }^{14}$ Within five years, more than half of patients will have returned to their baseline weight. Therefore, it is prudent to consider additional options beyond the traditional nutrition and exercise approach to weight loss, especially if sustained weight maintenance is desired. This includes surgery and weight loss medication. Unfortunately, the medical options available to assist weight loss are limited. This article reviews the potential role of lorcaserin, a new antiobesity agent, in the management of weight in obese patients with and without type 2 diabetes.

\section{Emerging therapy}

The number of pharmacotherapeutic agents available for the treatment of obesity has decreased in recent years because numerous agents, in particular dexfenfluramine and sibutramine, have been removed from the market as a result of serious side effects. ${ }^{15}$ In 2012, the US Food and Drug Administration (FDA) approved lorcaserin (Belviq ${ }^{\circledR}$, Arena Pharmaceuticals Inc, Zofingen, Switzerland) and a combined phentermine and controlled-release topiramate formulation $\left(\right.$ Qsymia $^{\circledR}$, Vivus, Mountain View, CA, USA), which were the first new oral antiobesity agents approved in 10 years. ${ }^{15}$ The phentermine and controlled-release topiramate combination uses two agents with differing mechanisms of action to provide additive weight loss effects while using lower doses of both agents, potentially reducing the risk of side effects. The phentermine-controlled-release topiramate formulation has been shown to decrease weight by an average of $12.2 \mathrm{~kg}$ over 52-104 weeks of treatment in three separate clinical studies. ${ }^{16-18}$ However, this formulation does not have a clear role in the treatment of obesity because it has not been compared directly with lorcaserin, other obesity treatments, or surgical intervention, such as gastric bypass. Given that this formulation is estimated to cost nearly $\$ 2200$ per year, ${ }^{19}$ its cost may limit its widespread use in the treatment of obesity.

\section{Lorcaserin}

Although the exact mechanism of action for lorcaserin is not clearly understood, it is believed to act as an agonist at central serotonin subtype $2 \mathrm{C}\left(5-\mathrm{HT}_{2 \mathrm{C}}\right)$ receptors located on hypothalamic pro-opiomelanocrotin neurons. Agonism of the $5-\mathrm{HT}_{2 \mathrm{C}}$ receptor is believed to reduce food intake and increase satiety, leading to weight loss. ${ }^{20-22}$ Lorcaserin shows high selectivity for the $5-\mathrm{HT}_{2 \mathrm{C}}$ receptor subtype, with minimal activity at $5-\mathrm{HT}_{2 \mathrm{~B}}$ or $5-\mathrm{HT}_{2 \mathrm{~A}}$ receptor subtypes. Earlier antiobesity agents, such as dexfenfluramine, were withdrawn from the market because of an association with valvular heart disease thought to be caused by agonism at the $5-\mathrm{HT}_{2 \mathrm{~B}}$ receptor.

Lorcaserin is an orally administered tablet that can be taken without regard to meals. Time to maximal serum concentrations is approximately 1.5-2 hours, and the elimination half-life is approximately 11 hours. Lorcaserin is approximately $70 \%$ protein-bound and undergoes hepatic metabolism to inactive metabolites which are mainly eliminated via the kidneys. No dosing adjustments are required in patients with mild-to-moderate hepatic or renal impairment. However, clinical experience is limited in patients with Child-Pugh class $\mathrm{C}$ hepatic impairment or a creatinine 
clearance in the range of $30-50 \mathrm{~mL}$ per minute, so caution is advised. It is not recommended to use lorcaserin in severe renal disease (creatinine clearance $<30 \mathrm{~mL}$ per minute). ${ }^{23}$ The three published studies involving lorcaserin are reviewed below and summarized in Table $1 . .^{20-22}$

The BLOSSOM trial included subjects aged 18-65 years with a body mass index (BMI) of $30-45 \mathrm{~kg} / \mathrm{m}^{2}$ or a BMI of $27-29.9 \mathrm{~kg} / \mathrm{m}^{2}$ and at least one weight-related comorbidity, such as hypertension, dyslipidemia, cardiovascular disease, impaired glucose tolerance, or obstructive sleep apnea. ${ }^{20}$ Key exclusion criteria were systolic blood pressure $>150 \mathrm{mmHg}$ or diastolic blood pressure $>95 \mathrm{mmHg}$, a diagnosis of type 2 diabetes, use of a selective serotonin reuptake inhibitor within the previous year, use of prescription weight loss medication within the previous three months, and use of over-the-counter weight loss drugs within the previous month.

The study enrolled 4008 subjects who were randomly assigned to lorcaserin $10 \mathrm{mg}$ once daily $(\mathrm{n}=801)$, lorcaserin $10 \mathrm{mg}$ twice daily $(\mathrm{n}=1602)$, or placebo $(\mathrm{n}=1601)$ for 52 weeks, in addition to standardized nutritional and exercise counseling, which was provided at each study visit. Participants were encouraged to exercise moderately for 30 minutes each day and to reduce their caloric intake by $600 \mathrm{kcal} /$ day. At baseline, the mean age of the patients was 44 years (79.8\% women, $67 \%$ white). Mean baseline body weight, waist circumference, and BMI was $100 \mathrm{~kg}$, $109 \mathrm{~cm}$, and $36 \mathrm{~kg} / \mathrm{m}^{2}$, respectively. Approximately 24\% of participants had hypertension, 28\% had dyslipidemia, and $1 \%$ had cardiovascular disease. ${ }^{20}$

The primary outcome was the proportion of subjects who lost at least $5 \%$ or $10 \%$ of their baseline body weight, and the analysis was conducted using a modified intention- to-treat approach with the last observation carried forward. The sample size was based on analysis of echocardiographic endpoints, and the study had $99 \%$ power to detect a $15 \%$ difference in the primary outcome between placebo and lorcaserin if 720 subjects were enrolled in each group. Echocardiograms were performed at baseline and again at weeks 24 and 52.

After one year of treatment, at least 5\% weight loss was achieved by $47.2 \%, 40.2 \%$, and $25 \%$ in the lorcaserin twice daily, lorcaserin once daily, and placebo groups, respectively ( $P<0.0001$ for both doses of lorcaserin versus placebo). More than $10 \%$ weight loss was achieved by $22.6 \%$ of those receiving lorcaserin twice daily, $17.4 \%$ of those receiving lorcaserin once daily, and $9.7 \%$ of those receiving placebo ( $P<0.001$ for both doses versus placebo). Absolute weight loss was $5.8 \mathrm{~kg}$ for lorcaserin twice daily, $4.7 \mathrm{~kg}$ for lorcaserin once daily, and $2.9 \mathrm{~kg}$ for placebo (calculated by the least squares means method). Fifty-five percent of participants completed the study. The results of the primary analysis were confirmed in post hoc sensitivity analysis.

Waist circumference decreased on lorcaserin $(P<0.001$ for both lorcaserin doses versus placebo). Changes in lowdensity lipoprotein were not significantly different between the groups, and according to the prespecified statistical plan, changes in other lipid parameters would not be assessed if changes in low-density lipoprotein were not significant. Glycosylated hemoglobin A1c, systolic and diastolic blood pressure, and heart rate all showed minor and statistically insignificant decreases. Quality of life was improved on lorcaserin (with a 1.8-point and 1.3-point difference for lorcaserin twice daily and lorcaserin once daily, respectively, compared with placebo, $P<0.001)$. The most common adverse events

Table I Summary of clinical studies of lorcaserin

\begin{tabular}{|c|c|c|c|c|}
\hline Study & Design and intervention & Results & $P$ value & Reference \\
\hline Fidler et al & $\begin{array}{l}\text { Randomized, double-blind, placebo- } \\
\text { controlled; lorcaserin } 10 \mathrm{mg} \text { bid, } \\
\text { lorcaserin } 10 \mathrm{mg} \text { qd, or } \\
\text { placebo } \times 52 \text { weeks }\end{array}$ & $\begin{array}{l}\text { At } 52 \text { weeks, weight loss }>5 \% \text { of BBW } \\
\text { occurred in } 47.2 \% \text { of lorcaserin } 10 \mathrm{mg} \text { bid } \\
\text { group, } 40.2 \% \text { of lorcaserin } 10 \mathrm{mg} \text { qd group, } \\
\text { and in } 25 \% \text { of placebo subjects }\end{array}$ & $\begin{array}{l}P<0.000 \text { I for both } \\
\text { doses versus placebo }\end{array}$ & 20 \\
\hline Smith et al & $\begin{array}{l}\text { Randomized, double-blind, placebo- } \\
\text { controlled; lorcaserin } 10 \mathrm{mg} \text { bid or } \\
\text { placebo } \times 52 \text { weeks; placebo continued } \\
\text { for } 52 \text { weeks, lorcaserin group randomized } \\
\text { in } 2 \text { : I ratio to continue lorcaserin } 10 \mathrm{mg} \\
\text { bid or placebo } \times 52 \text { weeks }\end{array}$ & $\begin{array}{l}\text { At } 52 \text { weeks, weight loss }>5 \% \text { of BBW } \\
\text { occurred in } 47.5 \% \text { of lorcaserin } 10 \mathrm{mg} \text { bid } \\
\text { group and } 20.3 \% \text { of placebo subjects }\end{array}$ & $P<0.001$ & 21 \\
\hline O'Neil et al & $\begin{array}{l}\text { Randomized, double-blind, placebo- } \\
\text { controlled; lorcaserin } 10 \text { mg bid, lorcaserin } \\
10 \text { mg qd, or placebo } \times 52 \text { weeks }\end{array}$ & $\begin{array}{l}\text { At } 52 \text { weeks, weight loss }>5 \% \text { of BBW } \\
\text { occurred in } 37.5 \% \text { of lorcaserin } 10 \mathrm{mg} \text { bid } \\
\text { group, } 44.7 \% \text { of lorcaserin } 10 \mathrm{mg} \text { qd group, } \\
\text { and } 16.1 \% \text { of placebo subjects }\end{array}$ & $\begin{array}{l}P<0.00 \text { I for both } \\
\text { doses versus placebo }\end{array}$ & 22 \\
\hline
\end{tabular}

Abbreviations: BBW, baseline body weight; bid, twice daily; qd, once daily. 
were headaches, upper respiratory tract symptoms and infections, nausea, dizziness, and fatigue. Lorcaserin had no effect on echocardiographic changes. Potential limitations of this study include its fairly homogeneous population of white women, being potentially overpowered for a safety outcome as opposed to an efficacy outcome, and of questionable efficacy with regard to diet and lifestyle counseling, given the marginal weight loss in the placebo group. ${ }^{20}$

The BLOOM study included subjects aged 18-65 years with a BMI of $30-45 \mathrm{~kg} / \mathrm{m}^{2}$. Those with a BMI of $27-30 \mathrm{~kg} / \mathrm{m}^{2}$ were also included provided they had one or more of the following: hypertension, cardiovascular disease, dyslipidemia, impaired glucose tolerance, or obstructive sleep apnea. Key exclusion criteria included a systolic blood pressure $>140 \mathrm{mmHg}$ or a diastolic blood pressure $>90 \mathrm{mmHg}$, diagnosis of type 2 diabetes, and depression or psychiatric illness requiring prescription drug treatment in the preceding two years. ${ }^{21}$

A total of 3182 subjects were enrolled and randomly assigned to receive lorcaserin $10 \mathrm{mg}$ twice daily $(\mathrm{n}=1595)$ or placebo $(\mathrm{n}=1587)$ for 52 weeks. Thereafter, subjects on the active treatment were randomized to either continue lorcaserin or placebo for another 52 weeks. Those originally assigned to placebo continued placebo. Approximately $50 \%$ of subjects completed the study. Lorcaserin was taken for two years continuously by 573 subjects, while 283 received lorcaserin and placebo for one year each; 697 received placebo for two years. All subjects received nutritional and exercise counseling at each visit and were encouraged to exercise moderately for 30 minutes per day as well as reduce their caloric intake by $600 \mathrm{kcal} /$ day. At randomization the mean age was 44 years, $67 \%$ of subjects were white, $19 \%$ were black, $83.5 \%$ were female, and the mean weight, BMI, and waist circumference was $100 \mathrm{~kg}, 36 \mathrm{~kg} / \mathrm{m}^{2}$, and $109 \mathrm{~cm}$, respectively. $^{21}$

The primary outcome was the proportion of patients who achieved $>5 \%$ weight loss, which was $47.5 \%$ in the lorcaserin group versus $20.3 \%$ in the placebo group (modified intention-to-treat population with last observation carried forward, $P<0.001$ ). Mean weight loss (using the least squares mean method for absolute weight loss) in the lorcaserin group was $5.8 \%(5.8 \mathrm{~kg})$ compared with $2.2 \%$ $(2.2 \mathrm{~kg})$ in the placebo group. At the end of the study, the proportion of patients able to maintain a weight loss $>5 \%$ was higher in the group that continued lorcaserin than in the group that switched to placebo $(67.9 \%$ versus $50.3 \%$, respectively, $P<0.001)$. Secondary outcomes included the proportion of patients achieving a $>10 \%$ weight loss, change in waist circumference, blood pressure change, and BMI. Of these, only the proportion achieving $>10 \%$ weight loss was statistically significant for the lorcaserin as compared with placebo $(P<0.001)$. The other secondary outcomes showed modest but insignificant improvements associated with lorcaserin. Overall, lorcaserin appears to be more effective than placebo in achieving a $>5 \%$ weight loss over 52 weeks, with benefits persisting for an additional 52 weeks.

The most common adverse effects of lorcaserin included upper respiratory tract infection, headaches, dizziness, nasopharyngitis, and nausea. The incidence of FDA-defined valvulopathy was not different between the groups, although the study only had $60 \%$ power to rule out a relative risk ratio of 1.5 due to its low rate of occurrence during the study. Other potential limitations include the study being potentially overpowered for the efficacy analysis because the sample size was based on echocardiographic endpoints; questionable effectiveness of the nutritional and exercise counseling; and potentially biased data at 104 weeks given that only participants remaining in the study at 52 weeks (ie, those likely obtaining the most benefit) were eligible to continue the study. Finally, it is unknown if the marginal difference in mean weight loss $(3.6 \mathrm{~kg})$ is of clinical importance. ${ }^{21}$

The BLOOM-DM study enrolled subjects aged $18-65$ years with a BMI of $27-45 \mathrm{~kg} / \mathrm{m}^{2}$, a diagnosis of type 2 diabetes, and a glycosylated hemoglobin A $1 \mathrm{c}$ of $7 \%-10 \%{ }^{22}$ At baseline, participants could only be receiving metformin and/or a sulfonylurea for their type 2 diabetes. Key exclusion criteria included: use of insulin, exenatide, or pramlintide; depression or psychiatric illness requiring prescription drug therapy within the last year; history of cardiac valve disease; myocardial infarction or stroke within the previous six months; unstable angina; and use of selective serotonin or norepinephrine reuptake inhibitors. ${ }^{22}$

Subjects were randomly assigned to one of three treatment groups, ie, lorcaserin $10 \mathrm{mg}$ twice daily $(\mathrm{n}=256)$, lorcaserin $10 \mathrm{mg}$ once daily $(\mathrm{n}=95)$, or placebo $(\mathrm{n}=253)$ and followed for one year. Subjects received nutritional and exercise counseling and were advised to reduce their caloric intake by $600 \mathrm{kcal} /$ day and exercise moderately for 30 minutes daily. At baseline, $54 \%$ of the participants were female, $61 \%$ were white, $21 \%$ were black, and the mean age was approximately 53 years. Mean baseline body weight and BMI was $104 \mathrm{~kg}$ and $36 \mathrm{~kg} / \mathrm{m}^{2}$, respectively. Echocardiograms were performed at baseline and at weeks 24 and 52 .

The proportion of patients achieving at least a 5\% weight loss was $45 \%$ in the lorcaserin once daily group, 38\% in the lorcaserin twice daily group, and $16 \%$ in the placebo group ( $P<0.001$ for both doses compared with placebo). 
Successful weight reduction of $\geq 10 \%$ was seen in $18.1 \%$, $16.3 \%$, and $4.4 \%$ of subjects assigned to lorcaserin once daily, lorcaserin twice daily, and placebo, respectively. The absolute weight loss (using the least squares mean method) for lorcaserin once daily, lorcaserin twice daily, and placebo was $5 \mathrm{~kg}, 4.7 \mathrm{~kg}$, and $1.6 \mathrm{~kg}$, respectively. Improvements in fasting blood glucose and glycosylated hemoglobin A1c were statistically significant in the lorcaserin group $(P<0.05$ for both lorcaserin doses as compared with placebo). There was no statistically different change in blood pressure in those receiving lorcaserin. Lorcaserin appears to be more effective than placebo in reducing baseline body weight in those with type 2 diabetes.

Headache, back pain, nasopharyngitis, and nausea were the most common adverse events noted with lorcaserin. Hypoglycemia was more common in the lorcaserin groups, but none of the episodes were categorized as severe. The incidence of FDA-defined valvular disease did not differ between the groups. Potential study limitations were a small sample size for the lorcaserin once daily group, questionable effectiveness of the nutritional and weight loss counseling, and unknown baseline medication use in patients with high blood pressure or hyperlipidemia. ${ }^{22}$

Lorcaserin is indicated in conjunction with diet and exercise for the treatment of obesity in adults with a BMI $\geq 30 \mathrm{~kg} / \mathrm{m}^{2}$ or a BMI of $\geq 27 \mathrm{~kg} / \mathrm{m}^{2}$ in presence of one or more comorbid conditions, including hypertension, type 2 diabetes, or dyslipidemia. ${ }^{20-22}$ Twelve weeks of treatment should be allowed before efficacy is assessed. Patients who have not experienced at least a $5 \%$ weight loss after 12 weeks are unlikely to have success with continued therapy. Potential side effects include headache, upper respiratory tract symptoms and infection, dizziness, nausea, constipation, fatigue, and dry mouth. The daily cost is approximately $\$ 4 .{ }^{24}$ Based on an average weight loss of $5.5 \mathrm{~kg}$ in the clinical trials, it will cost approximately $\$ 265$ for each $\mathrm{kg}$ of weight loss with lorcaserin.

\section{Patient perspectives}

The patient's perception of how a new medication affects their overall quality of life has an important role in the success of treatment. Compliance and quality of life often comes down to how well the patient feels the medication is working, the simplicity of dosing, and the number and severity of unwanted effects. With many treatments for obesity, discontinuation of therapy is a major factor to overcome and has been one of the factors limiting the evidence for these therapies. ${ }^{25}$ Discontinuation is often because of adverse effects or the patient's dissatisfaction with the efficacy of therapy. Aware of this, investigators in the clinical trials of lorcaserin assessed improvement in quality of life from the patient perspective using two questionnaires..$^{20-22}$ The first questionnaire used was the Impact of Weight on Quality of Life-Lite (IWQOL-LITE), which is a validated 31-item instrument addressing quality of life specifically in terms of obesity. ${ }^{26}$ IWQOL-LITE is sensitive to both weight loss and weight gain, as well as the degree of obesity. The scores range from $0-100$, with higher numbers correlating with better overall quality of life. The second questionnaire used was the Beck Depression Inventory (BDI)-II. This instrument is comprised of 21 questions designed to identify the severity of depression in an individual. ${ }^{27}$ Each question can be scored on a $0-3$ scale, and the total score is then used to distinguish between minimal ( $0-13$ points), mild (14-19 points), moderate (20-28 points), and severe (29-63 points) depression.

The BLOSSOM trial evaluated quality of life using both the IWQOL-LITE and BDI-II questionnaires. ${ }^{20}$ The surveys were given at randomization and at prespecified intervals thereafter, although the authors did not indicate the exact time point at which the questionnaires were administered. Participants were separated into one of three groups (see Table 1), and among other exclusions, those taking selective serotonin reuptake inhibitors within the previous year were excluded from this study.

The BLOSSOM trial reported a significant improvement in IWQOL-LITE score in all treatment groups. The lorcaserin $10 \mathrm{mg}$ twice daily group showed an 11.8-point increase and the lorcaserin $10 \mathrm{mg}$ once daily group showed an 11.3-point increase versus a 10.0-point increase in the placebo group ( $P=0.0057$ and $P<0.001$ versus placebo, respectively). These numbers were slightly higher in the per-protocol patients (participants who completed the study) at 12.2, 12.6, and 10.4 in the lorcaserin $10 \mathrm{mg}$ twice daily, lorcaserin $10 \mathrm{mg}$ once daily, and placebo groups, respectively $(P<0.001$ in both lorcaserin groups compared with placebo). The mean BDI-II total scores for lorcaserin twice daily, lorcaserin once daily, and placebo decreased by $-0.8 \pm 3.9,-0.8 \pm 4.1$, and $-0.7 \pm 3.8$ points, respectively. No statistical analysis was reported for these findings. ${ }^{20}$

Like many weight loss trials, the BLOSSOM study reported a relatively high discontinuation rate, with only $55 \%$ of the participants actually completing the trial. ${ }^{20}$ At the end of the study, the number of patients remaining in each group was similar at 917 (57.2\%), 473 (59.0\%), and $834(52.0 \%)$ in the lorcaserin 10 twice daily, lorcaserin $10 \mathrm{mg}$ once daily, and placebo groups, respectively. The 
investigators reported the reasons for withdrawal were loss to follow-up, adverse events, or a perception by the patient of a lack of efficacy. The proportion of patients that withdrew because of perceived lack of efficacy was similar between the groups at $2.4 \%$ and $3.1 \%$ in the lorcaserin $10 \mathrm{mg}$ twice daily and lorcaserin $10 \mathrm{mg}$ daily groups, respectively, and $3.9 \%$ in the placebo group. The BLOSSOM trial reports that compliance with treatment was monitored, but does not describe how this was assessed.

As in the BLOSSOM study, the BLOOM study also used the IWQOL-LITE and BDI-II surveys. ${ }^{21}$ Participants were separated into two groups (see Table 1), and among other exclusions, those with a diagnosis of depression or any other psychiatric condition requiring medical treatment within two years of randomization were excluded from the study.

IWQOL-LITE was conducted at baseline and at fourmonthly intervals thereafter during the trial. There was no significant difference in scores between the lorcaserin $10 \mathrm{mg}$ twice daily group or placebo group at baseline $(73.92 \pm 0.41$ and $73.85 \pm 0.42$, respectively). At the end of one year, scores were increased by $12.4 \pm 0.4$ in the lorcaserin group and
$10.7 \pm 0.4$ in the placebo group $(P<0.001)$ in the intentionto-treat analysis. ${ }^{21}$

The BDI-II questionnaire was administered at the screening visit and at nine subsequent visits. There was no difference between the lorcaserin $10 \mathrm{mg}$ twice daily group and placebo at baseline ( $4.2 \pm 0.1$ and $4.2 \pm 0.1$, respectively). After one year of treatment, scores were lower in the lorcaserin group compared with the placebo group $(1.1 \pm 0.1$ versus $0.9 \pm 0.1$, respectively), although the difference did not reach statistical significance $(P=0.26) .{ }^{21}$

A large discontinuation rate of nearly $50 \%$ was reported in the BLOOM trial, with a rate of completion of $55.4 \%$ in the lorcaserin group and $45.1 \%$ in the placebo group. The investigators do not offer any particular reason for this high dropout rate, other than a small percentage of participants reporting an adverse drug effect as the reason for withdrawal. Within the study procedures the authors simply stated that compliance to the study treatment was evaluated. There was no further mention of this in the study nor were there any specifics on how this evaluation was accomplished. ${ }^{21}$

BLOOM-DM reported quality of life measures as part of its secondary outcomes, and like the previous studies, used

Table 2 Patient satisfaction with lorcaserin

\begin{tabular}{|c|c|c|c|c|c|c|}
\hline Study & Placebo & $\begin{array}{l}\text { Lorcaserin } 10 \mathrm{mg} \\
\text { twice daily }\end{array}$ & $P$ value* & $\begin{array}{l}\text { Lorcaserin } 10 \mathrm{mg} \\
\text { once daily }\end{array}$ & $P$ value* & Reference \\
\hline \multicolumn{7}{|l|}{ BLOSSOM } \\
\hline IWQOL-LITE score (baseline) & $75.3 \pm 15.6$ & $74.7 \pm 16.1$ & & $75.5 \pm 16.0$ & & 20 \\
\hline Change from baseline & $10.0 \pm 10.1$ & $11.8 \pm 10.1$ & $<0.001$ & $11.3 \pm 10.3$ & $<0.001$ & \\
\hline \multicolumn{7}{|c|}{ BLOSSOM per-protocol population } \\
\hline IWQOL-LITE score (baseline) & $76.4 \pm 14.9$ & $74.6 \pm 15.9$ & & $76.4 \pm 15.5$ & & 20 \\
\hline Change from baseline & $10.4 \pm 9.9$ & $12.2 \pm 9.8$ & $<0.001$ & $12.6 \pm 9.8$ & $<0.001$ & \\
\hline BDI-II score & $4.2 \pm 0.1$ & $4.2 \pm 0.1$ & & & & \\
\hline Change from baseline & $-0.9 \pm 0.1$ & $-1.1 \pm 0.1$ & 0.26 & & & \\
\hline \multicolumn{7}{|l|}{ BLOOM ITT/LOCF } \\
\hline IWQOL-LITE score (baseline) & $73.85 \pm 0.42$ & $73.92 \pm 0.41$ & & N/A & N/A & 21 \\
\hline Change from baseline & $10.7 \pm 0.4$ & $12.4 \pm 0.4$ & $<0.001$ & $\mathrm{~N} / \mathrm{A}$ & N/A & \\
\hline \multicolumn{7}{|c|}{ BLOOM repeated-measures analysis } \\
\hline IWQOL-LITE score (baseline) & $73.85 \pm 0.42$ & $73.92 \pm 0.41$ & & N/A & N/A & 21 \\
\hline Change from baseline & $10.6 \pm 0.2$ & $12.4 \pm 0.2$ & $<0.001$ & N/A & $\mathrm{N} / \mathrm{A}$ & \\
\hline IWQOL-LITE score (baseline) & $74.0 \pm 17.6$ & $74.7 \pm 16.2$ & & $74.2 \pm 16.2$ & & \\
\hline Change from baseline & $10.2 \pm 0.7$ & $11.3 \pm 0.7$ & 0.221 & $12.6 \pm 1.1$ & 0.042 & \\
\hline BDI-II score & $4.0 \pm 3.6$ & $4.4 \pm 4.3$ & & $4.1 \pm 4.5$ & & \\
\hline Change from baseline & $-0.3 \pm 0.3$ & $-0.1 \pm 0.3$ & 0.669 & $-0.01 \pm 0.5$ & 0.630 & \\
\hline \multicolumn{7}{|c|}{ BLOOM-DM completer population } \\
\hline IWQOL-LITE & $73.5 \pm 18.7$ & $75.0 \pm 16.2$ & & $76.0 \pm 16.0$ & & 22 \\
\hline Change from baseline & $10.8 \pm 0.8$ & $11.5 \pm 0.8$ & 0.482 & $13.2 \pm 1.2$ & 0.058 & \\
\hline BDI-II & $3.8 \pm 3.5$ & $4.3 \pm 4.3$ & & $3.5 \pm 3.5$ & & \\
\hline Change from baseline & $-0.5 \pm 0.4$ & $-0.6 \pm 0.4$ & 0.887 & $-0.6 \pm 0.5$ & 0.903 & \\
\hline
\end{tabular}

Notes: *Compared between change in placebo group and change in intervention group; N/A group was not assessed in this trial.

Abbreviations: IWQOL-LITE, Impact of Weight on Quality of Life-Lite; BDI-II, Beck Depression Inventory-II; LOCF, last observation carried forward; ITT, intention-totreat. 
the IWQOL-LITE and BDI-II surveys. ${ }^{22}$ Participants were separated into three groups (see Table 1) and among other exclusion criteria, potential participants were excluded if they had a history of depression, another major psychiatric disease requiring treatment with prescription medication within the previous year, a BDI-II score $\geq 20$, or an individual response suggesting suicidal ideation.

The IWQOL-LITE questionnaire was completed at the baseline visit and again at 24 and 52 weeks. This score was reported to be improved in all treatment groups; however, only the lorcaserin $10 \mathrm{mg}$ daily modified intention-to-treat/ last observation carried forward cohort showed a statistically significant improvement of $12.6 \pm 1.1$ points compared with placebo $(P=0.042)$. The BDI-II survey was administered at baseline and again at weeks 4, 24, and 52. As mentioned earlier, BLOOM-DM excluded patients with moderate depression, as defined by this questionnaire. There was no difference in scores between any of the groups at baseline and the authors reported a nonsignificant reduction in scores in all groups at the end of the study period. ${ }^{22}$

Based on the findings of BLOOM-DM, lorcaserin $10 \mathrm{mg}$ once or twice daily may have had a slight benefit in reducing depression and achieving a slight improvement in overall QOL, with the $10 \mathrm{mg}$ daily modified intention-to-treat/ last observation carried forward cohort showing significant improvement. ${ }^{20}$ Adherence to study treatment was assessed by counting pills at each research visit. Patient's reported to be noncompliant to treatment regimen was reported at 3,1 , and 10 in the lorcaserin twice daily, once daily and placebo groups respectively. There was no statistical analysis for compliance between the groups reported. However, BLOOMDM did report a relatively high discontinuation rate of $22.1 \%$ for patients in the lorcaserin once daily group compared with $37.9 \%$ in the placebo group. ${ }^{22}$

Based on these trials, it appears that the effect of lorcaserin on weight loss may translate into a positive effect on overall quality of life. All three trials reported an improvement in IWQOL-LITE scores in the treatment groups, and some of the scores were reported to be significant when compared with placebo. Table 2 summarizes the patient satisfaction data. However, as with other weight loss medications, the high dropout rates seen in these trials may indicate poor compliance with lorcaserin which will likely affect its overall efficacy in many patients. ${ }^{20-22}$

\section{Conclusion}

Lorcaserin is a novel antiobesity agent affecting $5-\mathrm{HT}_{2 \mathrm{C}}$ receptors, and results in decreased food intake and increased satiety. It is effective in reducing weight in patients with and without type 2 diabetes. Presently it is unclear how this new agent fits into the treatment of obesity. In patients with type 2 diabetes, bariatric surgery has been shown to be more effective than pharmacologic therapy. ${ }^{28}$ However, those studies did not include the use of phentermine, topiramate or lorcaserin. Thus, no direct comparison between these agents and bariatric surgery can be made. Lorcaserin does appear to be accepted well by patients, and offers clinicians and patients an effective alternative to surgery. Weighing the risks and benefits of a new therapy is difficult, and future studies should address this.

\section{Disclosure}

The authors report no conflicts of interest in this work.

\section{References}

1. Flegal KM, Carroll MD, Kit BK, Ogden CL. Prevalence of obesity and trends in the distribution of body mass index among US adults 1999-2010. JAMA. 2012;307:491-497.

2. Centers for Disease Control and Prevention. National diabetes fact sheet: national estimates and general information on diabetes and prediabetes in the United States, 2011. Atlanta, GA: US Department of Health and Human Services, Centers for Disease Control and Prevention; 2011. Available from: http://www.cdc.gov/diabetes/pubs/factsheet11.htm. Accessed May 17, 2013.

3. Boyle JP, Thompson TJ, Gregg EW, Barker LE, Williamson DE. Projection of the year 2050 burden of diabetes in the US adult population: dynamic modeling of incidence, mortality, and prediabetes prevalence. Popul Health Metr. 2010;8:29.

4. Kramer H, Cao G, Dugas L, Luke A, Cooper R, Durazio-Arvizu R. Increasing BMI and waist circumference and prevalence of obesity among adults with type 2 diabetes: the National Health and Nutrition Examination Surveys. J Diabetes Complications. 2010;24:368-374.

5. Eckel RH, Kahn SE, Ferrannini E, et al. Obesity and type 2 diabetes: what can be unified and what needs to be individualized? J Clin Endocrinol Metab. 2011;96:1654-1663.

6. Inzucchi SE, Nauck M, Bergenstal RM, et al; American Diabetes Association (ADA); European Association for the Study of Diabetes (EASD). Management of hyperglycemia in type 2 diabetes: a patient centered approach. Position statement of the American Diabetes Association (ADA) and the European Association for the Study of Diabetes (EASD). Diabetes Care. 2012;35:1364-1379.

7. Ritter S, Vetter ML, Sarwer DB. Lifestyle modifications and surgical options in the treatment of patients with obesity and type 2 diabetes mellitus. Postgrad Med. 2012;1244:168-180.

8. Tuomilehto J, Lindstrom J, Eriksson JG, et al; Finnish Diabetes Prevention Study Group. Prevention of type 2 diabetes mellitus by changes in lifestyle among subjects with impaired glucose tolerance. $N$ Engl $J$ Med. 2001;344:1343-1350.

9. Ilanne-Parikka P, Eriksson JG, Lindstrom J, et al; Finnish Diabetes Prevention Study Group. Effect of lifestyle intervention on the occurrence of metabolic syndrome and its components in the Finnish Diabetes Prevention Study. Diabetes Care. 2008;31:805-807.

10. Ilanne-Parikka P, Laaksonen DE, Eriksson JG, et al. Leisure-time physical activity and the metabolic syndrome in the Finnish Diabetes Prevention Study. Diabetes Care. 2010;33:1610-1617.

11. Laaksonen DE, Lindstrom J, Tuomilehto J, Uusitupa M; Finnish Diabetes Prevention Study Group. Increased physical activity as a cornerstone in the prevention of type 2 diabetes in high-risk individuals. Diabetologia. 2007;50:2607-2608. 
12. Wadden TA, Butryn ML, Wilson C. Lifestyle modification for the management of obesity. Gastroenterology. 2007;132:2226-2238.

13. Sarwer DB, von Sydow Green A, Vetter ML, Wadden TA. Behavorial therapy for obesity: where are we now? Curr Opin Endocrinol Diabetes Obes. 2009;16:347-352.

14. Perri MG, Corsica JA. Improving the maintenance of weight loss in behavioral treatment of obesity. In: Wadden TA, Stunkard AJ, editors. Handbook of Obesity Treatment. 1st ed. New York, NY: Guilford Press; 2002.

15. Colman E, Golden J, Roberts M, Egan A, Weaver J, Rosebraugh C. The FDA's assessment of two drugs for chronic weight management. N Engl J Med. 2012;367:1577-1579.

16. Allison DB, Gadde KM, Garvey WT, et al. Controlled-release phentermine/topiramate in severely obese adults: a randomized controlled trial. Obesity. 2011;20:330-342.

17. Gadde KM, Allison DB, Ryan DH, et al. Effects of low-dose, controlled-release, phentermine plus topiramate combination on weight and associated comorbidities in overweight and obese adults (CONQUER): a randomised, placebo-controlled, phase 3 trial. Lancet. 2011;377:1341-1352.

18. Garvey WT, Ryan DH, Look M, et al. Two-year sustained weight loss and metabolic benefits with controlled-release phentermine/ topiramate in obese and overweight adults (SEQUEL): a randomized, placebo-controlled, phase 3 extension study. Am J Clin Nutr. 2012;95: 297-308.

19. US Food and Drug Administration. What is this new weight loss drug approved by the FDA? FDA Blogspot. Available from: http://fdabelviq. blogspot.com/. Accessed May 17, 2013.

20. Fidler MC, Sanchez M, Raether B, et al. A one-year randomized trial of lorcaserin for weight-loss in obese and overweight adults: the BLOSSOM trial. J Clin Endocrinol Metab. 2011;96:3067-3077.
21. Smith SR, Weissman NJ, Anderson CM, et al. Multicenter, placebocontrolled trial of lorcaserin for weight management. $N$ Engl J Med. 2010;363:245-256.

22. O'Neil PM, Smith SR, Weissman NJ, et al. Randomized placebo-controlled clinical trial of lorcaserin for weight loss in type 2 diabetes mellitus: the BLOOM-DM study. Obesity. 2012;20:1426-1436.

23. Belviq (lorcaserin hydrochloride) package insert. Zofingen, Switzerland: Arena Pharmaceuticals GmbH; 2012.

24. Flinn R, Edney A. Arena's Diet Pill May Spur Renewed Race From Drugmakers. Bloomberg. Retrieved from: http://www.bloomberg.com/ news/2012-2006-28/arena-s-diet-pill-may-spur-renewed-race-fromdrugmakers.html. Accessed May 17, 2013.

25. Fabricatore AN, Wadden TA, Moore RH, et al. Attrition from randomized controlled trials of pharmacological weight loss agents: a systematic review and analysis. Obes Rev. 2009;10:333-341.

26. Kolotkin RL, Thomas D. The Impact of Weight on Quality of Life-Lite (IWQOL-Lite). Office of Licensing and Ventures. Copyright 2013 Duke University. Available from: http://www.qualityoflifeconsulting.com/ iwqol-lite.html. Accessed April 10, 2013.

27. Beck AT, Steer RA, Brown GK. Beck Depression Inventory ${ }^{\circledR}-$ II. Copyright (C) 2012 Pearson Education Inc. Available from: http://www. pearsonassessments.com/HAIWEB/Cultures/en-us/Productdetail. htm?Pid=015-8018-370. Accessed April 8, 2013.

28. Schauer PR, Kashyap SR, Wolski K, et al. Bariatric surgery versus intensive medical therapy in obese patients with diabetes. $N$ Engl $J$ Med. 2012;366:1567-1576.

\section{Publish your work in this journal}

Diabetes, Metabolic Syndrome and Obesity: Targets and Therapy is an international, peer-reviewed open-access journal committed to the rapid publication of the latest laboratory and clinical findings in the fields of diabetes, metabolic syndrome and obesity research. Original research, review, case reports, hypothesis formation, expert opinion and commentaries are all considered for publication. The manuscript management system is completely online and includes a very quick and fair peer-review system, which is all easy to use. Visit http://www.dovepress.com/testimonials.php to read real quotes from published authors. 